\title{
Crime, violência e sociabilidades urbanas: as fronteiras da ordem e da desordem no sul brasileiro no final do séc. XIX
}

SANDRA JATAHY PESAVENTO*

\begin{abstract}
Resumo: $\mathrm{O}$ texto trabalha com as práticas sociais e as representações que dizem respeito ao crime e a violência na sociedade gaúcha no final do século XIX, analisando as tênues fronteiras entre os mundos da ordem e da desordem.
\end{abstract}

Abstract: The text works social practices and representations concerning crime and violence in the gaucho-society at the end of the $19^{\text {th }}$ century, analyzing the tenuous frontiers between the worlds of order and disorder.

Palavras-chave: Crime. Violência. Cidade. Sociabilidades. História cultural

Key words: Crime. Violence. City. Sociability. Cultural history.

Fora das definições clássicas do mundo da justiça, afinal, o que é a lei? É, sobretudo, a vontade humana de regrar o mundo, o social, os indivíduos. Criar normas de convivência harmônica, poderíamos dizer. Estabelecer interdições para que a violência e o crime não ocorram. Coibir comportamentos indesejáveis, poderíamos ainda acrescentar.

A lei é, pois, fruto de uma vontade e de um acordo entre os homens, ou, pelo menos, do comum acordo entre aqueles que a fazem. É resultado de uma negociação entre seus autores em face de uma questão posta pelo convívio social. Sendo determinação e vontade, é uma forma objetiva de normatização da vida ou do controle social que pressupõe uma representação da sociedade desejável. Ou seja, a lei dispõe, interdita, concede, tendo como referência padrões que os homens estabelecem através da história.

* Doutora em História Social pela Universidade de São Paulo, Professora do Departamento de História e dos Programas de Pós-Graduação em História e Planejamento Urbano e Regional da Universidade Federal do Rio Grande do Sul.

Estudos Ibero-Americanos. PUCRS, v. XXX, n. 2, p. 27-37, dezembro 2004 
E a história, como bem sabemos, tem sido, entre outras coisas, uma sucessão de formas de representação do mundo que os homens constroem socialmente. Assim sendo, podemos dizer que os homens constroem a realidade a partir de parâmetros imagináveis de sentido, sendo a formulação das leis uma de suas formas de ação.

Portanto, a justiça e o direito, que tratam das leis e de sua aplicação, implicam em instituição de saberes e práticas que, sempre historicizados, participam deste processo de atribuições de significado ao mundo. Definindo o que é permitido e o que é proibido, marcando os parâmetros da moral e do bem viver, o comportamento condenável e o ajustado, a norma e a transgressão, as leis e, por extensão, o delito conformam o social segundo representações paradigmáticas. Analisando as ocorrências da transgressão, temos a noção do que seja a norma desejada.

Por outro lado, no léxico urbano que preside o delineamento do mundo da transgressão nas cidades, é possível sempre surpreender práticas e atores excluídos, porque o vocabulário que os enuncia, tal como a ação também condenada que se quer coibir, nos induzem a resgatar outras normas, valores, necessidades e procedimentos que ocorrem com tanta freqüência quanto aquelas desejáveis no mundo da ordem.

É ainda esta linguagem que define o in e o out, que enuncia, delimita e classifica a inclusão e a exclusão, que induz o olhar e pauta o comportamento. Tais representações sociais, expressas pelo discurso que dá conta de espaços, atores e práticas, não é fruto apenas dos agentes de controle da urbe ou dos gestores da cidade. Sem dúvida que há uma linguagem culta, técnica, de elite, mas ela é intercambiável com a dos populares. Populares reconhecem, a priori que são os cidadãos, mas seus conceitos do que seja a ordem são diferentes. Para os cidadãos, o mundo dos excluídos é pura desordem, não vem aí uma lógica de comportamentos e valores.

Entretanto, tal como não é possível pensar em limites ou realidades isoladas entre a chamada cultura popular e a erudita, também é possível ver que são tênues as fronteiras entre o mundo da ordem e o da contra-ordem, da cidade dos cidadãos frente a cidade dos excluídos. Uns podem passar ao território do outro, e mesmo confundirem-se na prática de ações que a lei cidadã condena.

Tentemos analisar estas fronteiras móveis, da ordem e da desordem, na cidade de Porto Alegre, capital do estado do Rio Grande do Sul, o mais meridional do Brasil, naquele final do século XIX, onde se viviam os primeiros anos de uma república recém proclamada. 
A julgar pelas ocorrências encontradas nos jornais da cidade, parecia que, verdadeiramente, o pecado morava ao lado de cada moradia e que o crime espreitava em cada esquina... Mas, sem dúvida, há que estabelecer correlações entre as fontes a utilizar e analisar as informações que elas possam conter.

As linguagens variam também de forma significativa. $\mathrm{O}$ jornal estetiza o fato, ou seja, reorganiza a narrativa, encadeia o enredo, exprime um juízo de valor. Poderíamos dizer que o jornal informa, "literariamente", sobre o acontecido. Procura orientar a opinião, pela pena do jornalista, que por sua vez coloca a sua sensibilidade em confronto com o horizonte de expectativas de seu meio. Sentidos se superpõem, a narrar uma história que se pretende verídica, construída pelo discurso jornalístico. Já a documentação policial é mais regrada, existem mesmo fórmulas de registrar a ocorrência mas, mesmo assim, é fonte extremamente rica e polifônica. A fonte policial indica o ambiente da ocorrência do fato, se o mesmo foi registrado na delegacia por denúncia ou flagrante, dá conta das queixas e expõe os diferentes depoimentos das vítimas, agressores e testemunhas. É claro que são depoimentos condicionados, filtrados pela própria presença da autoridade e a gravidade do momento, mas a divergência de depoimentos ou os registros de linguagem utilizados permitem explorar muito bem as sociabilidades e sensibilidades de uma época, onde diferentes versões se estabelecem.

Aberto um processo e indo o acusado a julgamento, temos um outro caminho a cruzar com os anteriores. Os depoimentos são mais longos, há múltiplas versões para um mesmo fato, e é possível acompanhar também, mais de perto, a intervenção direta da justiça, com suas razões e fundamentações teóricas.

Mas nem sempre é possível acompanhar um caso que, noticiado no jornal, pode ser perseguido no registro policial e nos tribunais. Há lacunas, silêncios, ausências. Algo que surge com destaque nas páginas dos jornais, misteriosamente não consta nos registros policiais. Por vezes, ocorre o inverso: um promissor crime ou escandaloso incidente não é nem sequer registrado nos códices de entrada na polícia (os documentos teriam sumido?) ou dele não se acha o processo. Ou, então, é um volumoso processo criminal ao qual responde o silêncio dos periódicos e das fontes policiais, para desapontamento do historiador.

É, pois, um verdadeiro patchwork, este caminho de retraçar os crimes e a violência nas sociabilidades urbanas! Todo historiador sabe que tais descontinuidades são inevitáveis e, às vezes, ocorrem por razões bem simples: extravio de documentos, retirada para 
preservação ou mesmo outras razões que nunca conheceremos. Mas, sendo o método de construção da narrativa histórica uma renovada montagem, é na base deste quebra-cabeças que se possibilitam as explicações, pela composição das peças, as correspondências, as justaposições e os contrastes.

E é por este caminho que nos aventuramos, a buscar representações construídas sobre o crime na velha Porto Alegre no findar do século, onde uma elite ilustrada e cientificizada assumira o controle do poder com a implantação da República em 1889.

Porto Alegre era sede de um governo que tinha no positivismo sua matriz de inspiração política e administrativa. A elite dirigente de jovens bacharéis pretendia realizar um programa de racionalização da produção para atingir rápido progresso econômico conjugado à consolidação e manutenção de uma ordem social dada. Uma das premissas para este programa era regulamentar, disciplinar, controlar, vigiar, punir e excluir os personagens da contramão da ordem, as condutas indesejáveis e os espaços malditos da cidade. Em outras palavras, estabelecer as fronteiras entre os mundos da ordem e da desordem, definindo, por palavras e atos as delimitações entre as esferas da cidadania e da exclusão.

Para tanto, era essencial cercear aqueles que se expressavam e agiam fora dos marcos do que era entendido como a normalidade desejada. Os selvagens da cidade, os bárbaros urbanos apresentavam um perfil preciso: a julgar pelo Livro de Sentenciados da Casa de Correção de Porto Alegre, ${ }^{1}$ o criminoso típico era do sexo masculino, solteiro, altura média de 1,50 m (!), mestiço, analfabeto, na faixa etária dos 20 a 30 anos e jornaleiro ou diarista por ocupação, o que equivale dizer que não tinha profissão definida. E, basicamente, cometera homicídio, com emprego de arma branca: punhal, faca, estilete, espada.

No imaginário social da fin de siècle sul-brasileira, tais indivíduos perigosos eram, sobretudo, mestiços ou negros, e sempre definidos como vadios, desocupados e de maus instintos. Condição e perfil que, a priori, se chocava com os planos desta elite, ilustrada e cientificista, que queria controlar uma cidade bela, higiênica, ordenada e branca.

O léxico de estigmatização urbana da época, ao estabelecer as fronteiras da cidadania e da exclusão, definia como turbulento aquele que provocava desordem ou tumulto, por bebida ou briga, a provocar os demais, com palavras e gestos, chegando mesmo a

1 Livro de Sentenciados da Casa de Correção de Porto Alegre. 1874-1900. Manuscrito. Arquivo Histórico do Estado do Rio Grande do Sul. 
causar ferimentos leves. Indivíduos sem ofício nem benefício, seus atos iam desde atitudes mais simples, como algazarra, cantoria, bebedeira e correria pelas ruas, mas poderiam degenerar até os crimes de morte e roubo. Mais do que vadio e desordeiro, o turbulento poderia ser também um assassino, um criminoso no mais alto grau.

A postura cientificista da época, em interlocução com as mais recentes teorias da antropologia criminal da fin de siècle, debatia-se entre duas posições: a do renomado Cesare Lombroso, que afirmava que o indivíduo já nascia criminoso e que sua aparência externa revelaria, em traços visíveis, o seu íntimo condenável, e a de Alexandre Lacassagne, a postular que o meio social é que produzia o crime. Na Casa de Correção de Porto Alegre, o Doutor Sebastião Leão, médico renomado, realizava estudos minuciosos com os detentos, à frente do Laboratório de Antropologia Criminal, inaugurado em 1897. Haveria realmente um homo criminalis?

Para possibilitar o estudo, foi organizado um Álbum Fotográfico, a fim de analisar, registrar, catalogar e comparar os traços fisionômico dos presos. Após exame criterioso, durante o qual justamente os negros eram os mais intrigantes, por não conseguirem enquadrar-se nos parâmetros lombrosianos, o criterioso Doutor Leão concluiu pelo acertos das posições do francês Lacassagne: era o meio que favorecia o crime, admitia o doutor, com o que se justificavam medidas de controle e intervenção no social e se descortinavam possibilidades de recuperação, para o caminho da ordem, dos personagens da contramão da vida.

O imaginário social apontava os negros e mestiços como potenciais criminosos, tipos degenerados e situados num baixo plano na evolução da espécie humana. Mas, ao analisar seus presos e os delitos cometidos, o Doutor Leão era forçado a reconhecer que, mesmo os brancos - alemães, italianos, portugueses, poloneses, espanhóis - eram capazes de cometer os atos mais cruéis, requintados e premeditados...

No plano do enfrentamento da teoria com a prática, uma fronteira - racial e étnica- já era rompida, no que diz respeito ao crime e à desordem.

Mas a Casa de Correção é, na verdade, o ponto final de um percurso feito no mundo dos excluídos. A trajetória tem início nas ruas da cidade, neste espaço conflitivo do público, espaço partilhado por todos. É na rua que se defronta e se expõe a diferença e onde se exercita o registro de linguagem que nomeia o "outro". É ainda nas ruas da cidade que se exibem as práticas convenientes, consagradas pela moral, estética, saúde e justiça, de modo que é 
nesta mesma rua que se torna ostensivo o comportamento desviante. Nas ruas, praças e becos - as ditas vias públicas - e nos espaços construídos da socialidade "desviante" - bordéis, cortiços, botequins e casas de jogo - se registrava a maior parte daquelas práticas condenadas pelos códigos de posturas municipais e pelo código criminal.

A maior parte das ocorrências registrada nos jornais da capital diziam respeito ao $1^{-}$distrito, zona central, mais populosa e onde mais se exibia o desnível social. Mais do que isto, era neste reduto central que se identificava a "verdadeira cidade", aquela do seu núcleo histórico de origem e que fora, por duas vezes, "amuralhada". Foi neste espaço, onde as ruas principais entrecruzavam-se com os becos, que uma vizinhança espacial de desigualdade social se constituiu. Superpovoado, era este primeiro distrito o principal reduto das ocorrências policiais. O $2^{\circ}$ e o $3^{\circ}$ distritos, que também compunham a área urbana daquele final de século, e onde se localizavam os bairros e arraiais, registravam, da mesma forma, ocorrências de contravenções, mas não tão intensa como no $1^{0}$ distrito, onde é possível quase que traçar uma espécie de geografia do crime e da violência.

Mas há ruas e ruas, como bem sabemos. Há ruas que, mesmo sendo por definição artérias públicas, os usuários fazem dela o seu privado, como os becos. Ou inverteríamos a questão, a dizer que, nestes espaços, o privado se torna público, pela ação do usuário? A dualidade do público e do privado pode ser revelar, às vezes, superposta e confundida.

Do espaço público ao privado, a cidade explode em práticas de contravenção, que vão do delito simples ao crime. Notícias que dão conta das detenções no $1^{\circ}$ posto policial do $1^{\circ}$ distrito, congregam as ditas infrações mais simples, que são encabeçadas pela desordem, seguidas pela embriaguez, ofensas à moral pública (que talvez pudessem ser entendidas como "palavrões") e ferimentos leves, mas é também nas ruas e nas casas que ocorrem os graves ferimentos, os roubos e os assassinatos. Do registro policial notícia de jornal, a indicação da cor é carregada de uma conotação pejorativa para designar o infrator: o negro Antonio, a mulata Belinha, o crioulo Manoel, o pardo José. Ou seja, a representação do crime obedece aos padrões de referência valorativos de uma sociedade recém egressa do escravismo e que estigmatiza negros e mestiços.

Ao percorrer as ocorrências da desordem e do crime, começam as superposições entre espaços, práticas e atores. Como um palimpsesto, a cidade boa se interpenetra com a cidade má, os bons 
lugares são também espaço para a prática do crime, de modo que se tornam, eles também, maus lugares. Uma cidade dentro da outra, sobre a outra, a impor, pela geografia da contravenção, uma outra realidade que desafia a cidade ordenada dos cidadãos.

É certo que os becos, lugares malditos do urbano, situavamse em contigüidade com as ruas principais de Porto Alegre, encravados no coração da cidade, a definir espaços quentes, terreno fértil para a contravenção. Havia também certos lugares de segregação, que formavam como uma espécie de cinturão negro em torno da cidade, a definir ocupantes egressos da escravidão: a Colônia Africana e o Areal da Baronesa, espaços por excelência de crimes e desordens. Se formos compor uma espécie de mapa destas ocorrências, sem dúvida teremos um ponto onde elas se concentram: o célebre Beco do Poço, encravado no coração da cidade. Meca da prostituição, reduto de bordéis e tascas, nele o jôgo e a bebida imperavam, degenerando em cenas de escândalo à moral e a brigas a sopapos e a mão armada, levando até ao assassinato.

Mas os dados dos jornais e da polícia nos revelam que as práticas condenáveis ocorriam em todo o território urbano, a demonstrar uma geografia mais alargada que aquela dos becos e das zonas negras de Porto Alegre. Mesmo a centralíssima rua da Praia, ou a aristocrática cidade alta, onde se concentravam as mansões, registravam ocorrências policiais e criminais. Se os espaços se confundem, o território da cidade acaba por não delimitar as fronteiras entre o mundo da ordem e o da desordem.

A reincidência das notícias policiais nos periódicos poderia indicar, por um lado, a insuficiência do policiamento na cidade, bem como o desregramento da própria policia, que se misturava aos ladrões, vagabundos e prostitutas, a se confundir com eles na produção da desordem...2 A leitura atenta dos mesmos jornais nos revela que justo aqueles que deviam zelar pela ordem estavam, com muita freqüência, envolvidos em toda espécie de crime, violência e atos de flagrante desrespeito à lei...

Aos olhos dos habitantes, não eram só os turbulentos os suspeitos: a própria polícia se envolvia nos tumultos. Aqueles que deviam controlar a desordem, precisavam de controle! Podiam, mesmo, ser quase confundidos com os atores da contravenção! Diante da violência da cidade, da ousadia do crime, do desregramento dos desocupados e turbulentos, o que faziam os policiais? Freqüentavam os mesmos lugares, partilhavam dos mesmos hábitos, misturavam-se como os personagens do submundo!

2 A Gazetinha; Gazeta da Tarde, Correio do Povo, Jornal do comércio, A Federação. 
Nesta medida, uma outra fronteira se esfacela: se guardas e soldados roubam, surram, dão golpes de espada e cometem assassinatos, ou bebem cachaça em botequins com os bandidos e as prostitutas, qual a diferença entre tais atores no espaço urbano? Ridicularizados, os policiais eram chamados pelo povo de ratos brancos e os soldados, de morcegos, em alusão a certas características do uniforme, alcunha que era motivo para novos conflitos de rua. Logo, em termos de agentes da ordem e provocadores da desordem, as fronteiras eram tênues, e as práticas e agentes passavam de um a outro lado sem maior problema...

Uma outra forma de estabelecer os limites entre os mundos da ordem e da desordem dá-se a partir dos registros de linguagem e diz respeito à designação cidadão e indivíduo. Ora, o que é o cidadão? É aquele que paga impostos, que obedece a lei, que vota, que é proprietário ou paga aluguel, tendo contudo, domicílio fixo e ocupação certa. Em geral, os cidadãos são sempre os agredidos ou os que reclamam ou denunciam, junto às autoridades, os desregramentos e crimes praticados pelos indivíduos.

Os indivíduos são suspeitos, seja por seu aspecto, indumentária ou por freqüentarem certos lugares condenados. De um modo geral, os indivíduos roubam, são bêbados, estão sempre a fazerem arruaças e acabam presos, por praticarem crimes leves ou então mais graves, envolvendo ferimento e morte.

São ainda, em princípio, os indivíduos aqueles recolhidos ao xadrez, como medida preventiva. Freqüentemente, não são referidos por seu nome completo, mas por designativos de imprecisão: são eles, por exemplo, nomeados como João de tal, um certo Mateus, Maria, uma qualquer, ou ainda um fulaninho ou o crioulo. É clara a indeterminação de identidade, a revelar a desclassificação social e a condição de excluído. Só um atributo é preciso: tais indivíduos, assim nomeados, são potencialmente agressores, desordeiros, vadios, criminosos. Ainda no mesmo sentido estigmatizador são as referências de indicação da cor, junto à indeterminação do nome e à prática de uma contravenção: "Foi recolhida presa [...] a negra Idalina de tal, por ter roubado [...]", ${ }^{3}$ etc. etc.

Indivíduos são, pois, gente, pois, sem importância, conhecidos por um prenome, identificados pela estigmatização da cor, que só aparecem na esfera pública através da desordem e da contravenção.

Para os indivíduos, os cidadãos eram reconhecíveis. Desta forma é que um jornal da época noticiava que um indivíduo - um

3 Mercantil, 17 dez. 1897. 
negro, recém libertado da cadeia -, interpelara uma vítima, ao assaltá-lo com uma faca: "Cidadão, alto lá!"4 Em tempos de pósRepública, a designação era corrente, mas a cidadania não era para todos, o que era perfeitamente compreendido por aqueles que eram excluídos deste pertencimento. E remarcável que, mesmo na hora de um assalto, o agressor invoque sua vítima por tal tratamento de distinção social e que o exclui.

Os cidadãos são, em geral, os atacados e os ameaçados pela violência das ruas, mas às vezes situam-se também na contramão da ordem! Os cidadãos, mesmo os das melhores e mais bem sucedidas famílias da cidade, podiam ser os agentes da agressão e do distúrbio na cidade. Assim é que encontramos notícias de que os cidadãos discutiam e chegavam mesmo à lutas corporais na rua ou em cafés, conflitos estes que, por vezes, degeneravam um tiros de pistola ou golpes de adaga ou bengala. Cidadãos compareciam ainda nas páginas policiais como defloradores de menores, como provocadores de briga, atuando de chicote e punhal na mão ou ainda a freqüentarem bordéis e botequins, locais que, a rigor, um verdadeiro cidadão não freqüentaria...

Por vezes, nestes incidentes de alteração da ordem pública, a palavra cidadão pode ser substituída por senhor nos registros policiais. O tipo de tratamento dado indica bem que se tratavam de pessoas de nível social elevado e de prestígio na cidade, mesmo que situando-se no mundo da dita desordem. Quando um jornal noticiava que dois senhores se haviam agredido a tiros em uma das artérias principais da cidade, noticiando em outro momento do mesmo periódico que o crioulo Zeca de tal dera um tiro em um certo Tonico, mulato, estamos diante de um mesmo ato de violência do cotidiano da cidade, onde as fronteiras se traçam no plano do simbólico. Os senhores desordeiros eram, por certo, cidadãos proprietários que, mesmo autuados em flagrante, pagaram fiança e foram soltos, enquanto que os dois indivíduos, indicados como sendo de cor (não-brancos) por certo teriam passado, no mínimo, alguns dias na Cadeia...

Sobre os excluídos, aplicavam-se os rigores da lei, construída na exemplaridade de fornecer ao social os castigos devidos aqueles que haviam ousado reverter a ordem pública. Uma vez cidadão infrator, a lei corrigia seus excessos, invertendo, por vezes, a situação: um senhor de 40 anos, casado e bem sucedido na vida, fora denunciado por uma pobre viúva de que ele seduzira ou violentara sua filha de 14 anos? Testemunhas garantiam: ele não fora o pri-

4 Correio do Povo, 8 jan. 1898. 
meiro, a menina já se encontrava prostituída há anos, etc. etc. etc. As fronteiras se erguiam, mágicas, na defesa dos donos da urbs, isolando os excluídos na esfera da contravenção, do mundo nãocidadão. O destino da menor era, pois, o bordel...

Mas, em termos de violência e desordem, os mundos da cidadania e da exclusão se interpenetravam ainda sob mais um aspecto: nos anos de 1893 a 1895, o Rio Grande do Sul foi sacudido por uma revolução, onde se enfrentaram os republicanos, detentores do poder, e os chamados federalistas ou maragatos, formados por parte das elites que haviam sido derrubadas do governo com a proclamação da República. Esta revolução, conhecida como revolução da degola, foi marcada por atos de barbarismo e selvageria. Um e outro lado dos contendores celebrizaram-se por matar o inimigo à faca, degolando-o. Nos campo de batalha, a sinistra prática tornou-se freqüente, mesmo que tais notícias fossem censuradas nas páginas dos jornais das cidades, a mostrar a violência nas práticas sociais, executadas por gente das camadas sociais mais baixas do campo, mas a mando das elites rivais.

E, neste ponto, chegamos à mais um espaço de diluição das fronteiras entre o mundo da ordem e da desordem, se o formos enfocar desde as cidades: esta violência presente no cotidiano das relações sociais urbanas tinha correspondência com outro tipo de violência disseminada pelo estado.

Razões para isso? Talvez pudéssemos buscar, para esta violência, por assim dizer, histórica, a própria formação do Rio Grande do Sul, única zona de fronteira viva com os castelhanos no passado da América do Sul. Região fronteiriça, a conquista da terra e do gado deu-se sempre de armas na mão. Em bandos armados, as tropas irregulares da campanha gaúcha serviram para a consolidação da fronteira sul e assentaram as bases de uma sociedade militarizada e baseada nas formas de mando autoritárias. Os ditos valores masculinos - força, coragem, bravura nas armas - mesmo que associados à disciplina e obediência, podiam degenerar em práticas violentas nas relações sociais. Note-se que a filosofia da degola era a de infligir ao inimigo, mesmo um guerreiro, uma morte inglória: como os animais, morrer pela faca, e sem armas na mão.

Já na cidade, a violência cotidiana pode ser aferida também por certos detalhes das notícias de jornal, que mostram que o uso de armas era freqüente e natural. Aparentemente, tem-se a impressão que todos, os turbulentos e os cidadãos andavam sempre armados, mesmo que se saiba que isso era proibido. O que parece, pois, se confirmar, é o panorama de uma cidade onde, entre a disposição legal e a prática das pessoas, não havia muita coincidência... 
Se era proibido, como explicar que, em quase todos os registros policiais, se sacava da adaga, punhal ou faca, em meio à discussão? Ao menor insulto, o ofendido, imediatamente, se valia de uma arma que trazia consigo, ferindo o outro.

O gesto equivocado, a palavra mal dita, o sentido dúbio degeneravam em conflito e drama. Passar da ofensa, injúria, ou mesmo discussão ao emprego das armas era coisa rápida, e as diferenças se estabeleciam entre a natureza das mesmas armas: os cidadãos usavam bengalas, punhais e revólveres, os indivíduos faca, navalha, estilete, pedaços de pau...

Tão difundido era o uso das armas que mesmo crianças eram vítimas a comparecer nas páginas dos jornais, por dispararem os revólveres dos pais, quando brincavam com eles.

Mais uma vez, se confirma uma diluição de fronteiras entre o mundo da ordem e da desordem na cidade de Porto Alegre no final do século XIX. Se a assimetria social ou a desigual apropriação do solo permitia a construção de bem marcadas representações de identidade urbana, opondo o mundo dos cidadãos aos dos excluídos, no plano das relações sociais, as práticas invadiam territórios, atravessando fronteiras, na aproximação das ações violentas, disseminadas, partilhadas. 